\title{
A Realidade do Gerenciamento de Resíduos de Lâmpadas que Contenham Mercúrio no Setor de Comércio de Materiais Elétricos no Município de Cuiabá/MT.
}

\section{The Reality of the Management of Waste Lamps Containing Mercury in the Trade Sector of Electrical Materials in the City of Cuiabá/MT (brazil).}

\author{
${ }^{1}$ Marco Henrique Oliveira Pultrini, ${ }^{2}$ Simone Raquel Caldeira Moreira da Silva \\ ${ }^{1}$ Engenheiro Eletricista / Electrical Engineer \\ (marcopultrini@outlook.com) \\ ${ }^{2}$ Doutora em Geoquímica / Doctor in Geochemistry \\ (simone@simone.bio.br)
}

Enviado em: Abril de 2016. Aceito em:Maio de 2016. Publicado em:Novembro de 2016

Resumo:A publicação da Lei n. ${ }^{\circ} 12.305$ de 02 de agosto de 2010 - Política Nacional de Resíduos Sólidos (PNRS) introduz princípios já conhecidos na área ambiental, mas pouco utilizados pelo público. Um destes princípios é a logística reversa. Este trabalho realizou um levantamento com as cinco empresas de maior representatividade no setor de comércio de materiais elétricos no município de Cuiabá/MT. O principal objetivo foi conhecer a realidade do gerenciamento de resíduos devolvidos de lâmpadas que contenham mercúrio. Utilizou-se de entrevistas com gerentes das empresas escolhidas, onde foram avaliadas informações a respeito de conhecimento da legislação, aplicação desta, gerenciamento dos resíduos, dentre outras. Os resultados demonstraram que no município de Cuiabá, não há alternativa adequada para a devolução de lâmpadas de mercúrio.

Palavras-Chave:Logística reversa. Exposição ocupacional. Responsabilidade compartilhada. Gestão e controle.

\section{Abstract:}

The publication of the Law No. 12.305 of 02 august 2010 - National Solid Waste Policy (PNRS) introduces principles known in the environmental area, but little used by the public. One of these principles is the reverse logistics. This work conducted a survey with the five most representative companies in the electrical materials trading sector in the city of Cuiabá/MT (Brazil). The main objective of the research was to know the reality of waste management returned lamps containing mercury in the sector. We used interviews with managers of the selected companies, which were evaluated information regarding knowledge of legislation, implementation of this, waste management, among others. The results showed that in the city of Cuiabá, there is no suitable alternative to the return of mercury lamps.

KEYWORDS: Reverse logistic. Occupational exposure. Shared responsibility.Management and control.

\section{INTRODUÇÃO:}

Em descrição histórica, a utilização do termo "mercúrio", para representação do elemento químico homônimo, provém de ideias de culturas árabes da Idade Média que associavam a característica de volatilidade do metal com o planeta Mercúrio, já que para os antigos, o astro movia-se mais rapidamente que os demais (Greenberg 2009).
Naturalmente encontrado na crosta terrestre, o mercúrio ocorre no ar, no solo e na água, podendo assumir em seu ciclo sua forma química elementar (mercúrio metálico),inorgânica, como os sais mercúricos e mercurosos, e orgânica, quando há a associação do mesmo com radicais de carbono originando compostos como o metilmercúrio (Azevedo et al. 2003)

Efeitos adversos importantes sobre a saúde humana são atribuídos ao mercúrio. A exposição a níveis elevados 
pode afetar o cérebro, o coração, os rins, os pulmões e o sistema imunológico dos seres humanos. A toxicidade varia de acordo com a sua forma química, a concentração, a via de exposição e a vulnerabilidade do indivíduo exposto (Nascimento e Chasin, 2001).

Nos Estados Unidos, a Agency for Toxic Substances \& Disease Registry (ATSDR), publica a cada dois anos a Substance Priority List (SPL), que em 2015, conta com o mercúrio na terceira colocação. A classificação leva em consideração uma combinação de sua frequência, toxicidade e potencial de exposição humana nos territórios cadastrados na base de dados da National Priorities List (NPL) da Environmental Protection Agency (EPA).

Levando em consideração sua nocividade, o controle sobre o uso do mercúrio na cadeia produtiva tem se intensificado em nível mundial. Com relação ao assunto, o maior expoente é a Convenção de Minamata, tratado que visa principalmente à proibição de novas minas de mercúrio, eliminação progressiva das já existentes, medidas de controle sobre as emissões atmosféricas e a regulamentação internacional do setor informal para mineração artesanal e de ouro em pequena escala. Ao todo 128 países já assinaram o documento e 24 nações o ratificaram (UNEP 2016).

O Brasil, um dos signatários, vem tentando superar a fase de diagnóstico do metal em território nacional. Existem estudos ambientais que abordam o uso do mercúrio na extração de ouro artesanal e em pequena escala, mas são escassas as informações sobreas outras 43 categorias de fontes mencionadas no Mercury Toolkit do United Nations Environment Programme (UNEP), conjunto de ferramentas para identificação e quantificação das emissões de mercúrio, dentre as quais figuram as fontes luminosas (lâmpadas elétricas) com mercúrio (UNEP 2015; MMA 2015).
No mercado brasileiro, temos à disposição os seguintes tipos de lâmpadas elétricas que empregam mercúrio: lâmpadas fluorescentes tubulares, lâmpadas de vapor de sódio a baixa e alta pressão, lâmpadas de vapor de mercúrio, lâmpadas de luz mista, lâmpadas de vapor metálico e por fim as lâmpadas fluorescentes compactas, que após a crise energética do ano de 2001, com a promessa da vida útil prolongada e maior eficiência energética, quando comparadas as tradicionais lâmpadas incandescentes, se multiplicaram exorbitantemente(Silva 2008; Goeking 2009).

Um dos grandes desafios da atualidade é, justamente, a gestão dos resíduos destes produtos, já que estão atrelados diretamente a uma das formas de contaminação por mercúrio, a exposição ocupacional direta e indireta.

Com o advento da Lei n. ${ }^{\circ} 12.305$ de 02 de agosto de 2010- Política Nacional de Resíduos Sólidos (PNRS), foram instituídas as diretrizes acerca do gerenciamento de resíduos sólidos, incluindo os perigosos, como é o caso dos resíduos das lâmpadas mencionadas. Nela ficam claramente definidas as regras para implantação dos planos de gerenciamento de resíduos, e dos sistemas de logística reversa, eliminando quaisquer interpretações dúbias acerca da responsabilidade pelo ciclo de vida destes materiais.

Neste contexto, introduzimos a proposta dotrabalho que é conhecer a realidade do gerenciamento de resíduos devolvidos de lâmpadas que contenham mercúrio no setor de comércio de materiais elétricos no município de Cuiabá/MT.

\section{MATERIAL E MÉTODOS:}

A metodologia de trabalho baseouse, primeiramente, na caracterização, quanto à periculosidade, dos resíduos de lâmpadas elétricas que usam mercúrio. Para tal, foi utilizado como material 
técnico de consulta, a norma brasileira ABNT NBR 10004:2004 - Resíduos sólidos - Classificação da Associação Brasileira de Normas Técnicas, atendendo a prescrição contida na Política Nacional de Resíduos Sólidos (Lei n. ${ }^{\circ} 12.305$ de 02 de agosto de 2010), em seu art. 13, inciso II, alínea "a".

Consultando ainda a lei mencionada, foi possível consolidar as obrigações imputadas aos comerciantes destas lâmpadas, bem como alguns dos métodos de gestão e controle atribuídos ao poder público, em suas esferas municipal e federal, no que tange à gestão dos resíduos devolvidos destes produtos.

Outro material técnico examinado foi a norma ABNT NBR 12235:1992 Armazenamento de resíduos sólidos perigosos, de modo a avaliar pontualmente os atributos exigidos destes comerciantes em sua característica de operadores (armazenamento) de resíduos perigosos.

Condensando as informações, foi desenvolvido um questionário contendo questões fechadas voltadas à obtenção de dados estatísticos acerca do gerenciamento de resíduos sólidos de lâmpadas elétricas com mercúrio devolvidas no setor de comércio de materiais elétricos na cidade de Cuiabá/MT.

As perguntas elaboradas tiveram como enfoque a observação dos modelos vendidos, das ações voltadas à logística reversa, da adequação das instalações para recepção dos resíduos, da aplicabilidade da responsabilidade compartilhada pelo ciclo de vida dos produtos e de ações voltadas ao controle da gestão pelo poder público municipal e federal.

Através de entrevistas estruturadas, realizadas entre as datas de 02 a 11 de fevereiro de 2016, o questionário foi aplicado nas cinco empresas de maior representatividade do setor de comércio de materiais elétricos no município. Como critério de escolha foi utilizado o capital social das empresas, cujas importâncias foram obtidas através de consulta no endereço eletrônico da receita federal.
Todos os funcionários entrevistados eram gerentes das lojas.

A Tabela 1 remete ao panorama de seleção dos estabelecimentos:

Tabela 1: Seleção das empresas.

\begin{tabular}{lcc}
\hline EMPRESA & $\begin{array}{c}\text { CNAE } \\
\text { PRINCIPAL/SECUNDÁRIA }\end{array}$ & $\begin{array}{c}\text { CAPITAL SOCIAL } \\
\text { (R\$) }\end{array}$ \\
\hline A & $47.42-3-00 / 46.73-7-00$ & $2.000 .000,00$ \\
B & $/ 46.73-7-00$ & $600.000,00$ \\
C & $/ 46.73-7-00$ & $400.000,00$ \\
D & $/ 47.42-3-00$ e $46.73-7-00$ & $700.000,00$ \\
E & $47.42-3-00 / 46.73-7-00$ & $1.500 .000,00$ \\
\hline
\end{tabular}

Cabe salientar que os Códigos Nacionais de Atividades Econômicas CNAE, 47.42-3-00 e 46.73-7-00, se referem, respectivamente, à atividade de comércio varejista e atacadista de material elétrico.

Por fim, as respostas foram compiladas em uma planilha computacional de modo a facilitar a interpretação quantitativa dos resultados.

\section{RESULTADOS E DISCUSSÕES:}

Segundo a norma técnica ABNT NBR 10004:2004 os resíduos de lâmpadas com mercúrio são classificados como perigosos (classe I), identificados no Anexo A do documento sob o código F044, e sua condição de periculosidade, se deve à toxidade do constituinte perigoso, $\mathrm{o}$ mercúrio.

A responsabilidade compartilhada pelo ciclo de vida destes resíduos se encontra muito bem definida na Política Nacional de Resíduos Sólidos (PNRS - Lei n. ${ }^{\circ} 12.305$ de 02 de agosto de 2010), onde todo comerciante de lâmpadas mercuriais é obrigado a estruturar e implementar, em conjunto com fabricantes, importadores e distribuidores, sistema de logística reversa para tais produtos. Sua participação no 
processo se enquadraria na função de operador armazenador dos resíduos, atentando-se para as exigências intrínsecas à classificação mencionada no parágrafo anterior.

Quando das respostas ao questionário, todas as empresas entrevistadas informaram vender algum tipo de lâmpada que contém mercúrio, onde, $100 \%$ mencionaram vender lâmpadas fluorescentes tubulares, fluorescentes compactas, lâmpadas de vapor de mercúrio, lâmpadas de vapor de sódio (alta pressão) e lâmpadas de vapor metálico; $80 \%$ disseram vender lâmpadas de luz mista e $60 \%$ afirmaram vender lâmpadas de vapor de sódio (baixa pressão).

Apesar destes números, apenas 40\% das empresas entrevistadas (empresas B e E) possuem uma política, isto é, praticam, ainda que de maneira falha, a logística reversa das lâmpadas devolvidas. Para todas as demais não se trata de um conceito em processo de criação.

Outro aspecto a se considerar é a falta de uma matriz de responsabilidades dentro da própria organização. Quando questionados sobre a existência de um departamento específico para as tratativas acerca da logística reversa das lâmpadas devolvidas contendo mercúrio, $80 \%$ dos entrevistados afirmaram não ter um departamento que se responsabiliza pelo segmento. A empresa $\mathrm{B}$ foi a única $\mathrm{a}$ responder à questão de modo afirmativo, indicando que a responsabilidade era atribuída ao setor de logística convencional da empresa, resposta no mínimo controversa, já que para operar com estes resíduos há necessidade de comprovar capacidade técnica para tal (PNRS - art. 37).

Ainda quanto à técnica, é notória a importância da condensação e atualização periódica das informações relativas ao gerenciamento dos resíduos perigosos de lâmpadas devolvidas. Este papel é atribuído aos planos de gerenciamento descrito no art. 39 da PNRS.
Os planos de gerenciamento destas lâmpadas são primordiais para a conclusão do diagnóstico nacional do mercúrio, uma vez que partem da premissa de conter um inventário acerca destes materiais. Quanto a este quesito, $80 \%$ dos estabelecimentos entrevistados informaram não dispor de um plano de gerenciamento que englobasse a logística reversa das lâmpadas devolvidas.

A falta de um plano afeta também a etapa de devolução dos resíduos perigosos de lâmpadas já que em seu conteúdo devem estar previstas as ações para o recolhimento dos resíduos e ações de divulgação de informações relativas às formas de evitá-los, reciclá-los e eliminálos.

Conforme dispõe a PNRS, comprar produtos já utilizados e disponibilizar postos de coleta são medidas que podem ser adotadas para a implementação e operacionalização de um sistema de logística reversa. Neste sentido, 100\%dos estabelecimentos entrevistados informaram não praticar nenhuma das medidas mencionadas.

Quanto às ações de divulgação de informações de sensibilização e até mesmo de educação quanto aos resíduos de lâmpadas, apenas $20 \%$ dos estabelecimentos informaram divulgá-las (empresa B). Esta empresa adota campanhas publicitárias sobre a tecnologia L.E.D. (Light Emitter Diode), disseminando informações acerca da contenção da geração dos resíduos com a adoção desta tecnologia.

O reflexo destes dois últimos percentuais se verifica nos comentários da empresa $\mathrm{E}$, ao mencionar que estão aptos a receber os resíduos, mas que poucos clientes os procuram para efetuar $o$ procedimento de restituição.

A escassez de dados sobre os quantitativos das lâmpadas contendo mercúrio que saem das "prateleiras" dos entrevistados também é alarmante. Conhecer o volume dos resíduos sobre sua responsabilidade é um fator primordial para o dimensionamento de um abrigo 
seguro e para a manutenção de uma gestão adequada.

Nenhuma das empresas entrevistas forneceu os quantitativos, estratificados por mês, de lâmpadas contendo mercúrio, vendidas no ano de 2015. Os gerentes alegaram dificuldade na obtenção dos dados. A empresa B forneceu somente os quantitativos referentes às unidades vendidas ao todo no ano mencionado por modelos e por categoria em alguns casos(Tabela 2).

Tabela 2: Lâmpadas vendidas pela empresa B em 2015.

\begin{tabular}{cc}
\hline $\begin{array}{c}\text { MODELOS/CATEGORIA } \\
\text { DE LÂMPADAS }\end{array}$ & $\begin{array}{c}\text { QUANTIDADE } \\
\text { VENDIDA EM } \\
\mathbf{2 0 1 5} \text { (UN) }\end{array}$ \\
\hline LÂMPADA & 33.000 \\
FLUORESCENTE & \\
TUBULAR & 58.000 \\
LÂMPADA & \\
FLUORESCENTE & \\
COMPACTA & 4.800 \\
LÂMPADAS & \\
MERCURIAIS DE & \\
DESCARGA DE ALTA & \\
PRESSÃO & 41.000 \\
LAMPADAS COM & \\
TECNOLOGIA & \\
L.E.D. & \\
\hline
\end{tabular}

Estratificar os quantitativos é
interessante para dimensionamento do abrigo para lâmpadas conforme a ABNT NBR 12235:1992, levando em consideração o fator econômico da construção.

Com relação especificamente a esta norma técnica (ABNT NBR 12235:1992), $60 \%$ das empresas entrevistadas revelaram desconhecer seu conteúdo. Considerando as empresas que afirmaram ter uma política acerca da logística reversa das lâmpadas devolvidas, apenas a empresa B conhece o conteúdo da normativa, mas indicou que o abrigo para os resíduos de lâmpadas devolvidos da empresa não atende aos seus requisitos.

Levando em consideração que o comércio é apenas um dos elos da cadeia, as empresas foram indagadas sobre os vínculos com os fabricantes de lâmpadas mercuriais. Um total de $80 \%$ dos entrevistados disse nunca ter sido contatado pelos fabricantes com o intuito de assumirem a sua parcela de responsabilidade. A exceção, empresa B, informou que, há pelo menos dois anos atrás, algumas empresas fabricantes ainda se responsabilizavam pela coleta de seus produtos no estabelecimento, entretanto, a parceria não existe mais.

Como modelo alternativo, as empresas que praticam a logística reversa das lâmpadas devolvidas, empresas B e E, contratam os serviços de empresas recicladoras para efetuar o manejo dos resíduos. Segundo o representante da empresa B, os altos custos destes serviços inviabilizam a recepção das lâmpadas de mercúrio em sua totalidade. Atualmente a empresa B aceita apenas os resíduos de seus grandes clientes.

Possíveis métodos de gestão e controle dos resíduos de lâmpadas por parte do poder público também foram objetos da avaliação. No âmbito municipal, quando perguntado às empresasse as mesmas já pagaram ou pagavam algum imposto em virtude das lâmpadas vendidas por eles terem sido recolhidas por órgão do poder público do município, $100 \%$ das empresas disseram nunca terem sido acionadas neste sentido. A remuneração do titular do serviço público de limpeza urbana e de manejo de resíduos sólidos pelo serviço encontra-se embasada na PNRS (art.33/\$ $/ 7^{\circ}$ ), desde que haja acordo setorial ou termo de compromisso firmado com o setor empresarial.

O Ministério do Meio Ambiente MMA na figura do Instituto Brasileiro do Meio Ambiente e dos Recursos Naturais Renováveis - IBAMA, através da Instrução Normativa IBAMA n. ${ }^{\circ}$ 1/2013, regulamenta o Cadastro Nacional de Operadores de Resíduos Perigosos CNORP, previsto na PNRS, do qual todas as empresas operadoras deveriam ser participantes. No entanto, quanto à sua existência, se provou o desconhecimento por parte de $40 \%$ das empresas entrevistada, e as outras $60 \%$ disseram conhecê-lo, mas revelaram, novamente, 
estar em desacordo com a obrigatoriedade do cadastramento previsto na legislação.

\section{CONCLUSÕES:}

A população geradora de resíduos de lâmpadas mercuriais, do município de Cuiabá/MT, não tem alternativa adequada para a devolução destes materiais, uma vez que nenhuma empresa entrevistada lhe disponibiliza um sistema de logística reversa em consonância com a Política Nacional de Resíduos Sólidos (PNRS - Lei n. ${ }^{\circ} 12.305$ de 02 de agosto de 2010).

\section{AGRADECIMENTOS:}

Agradeço à Dr. ${ }^{\text {a }}$ Simone Raquel Caldeira Moreira da Silva pelas importantes contribuições na construção do conhecimento para elaboração da pesquisa.

\section{REFERÊNCIAS:}

\section{AGENCY FOR TOXIC SUBSTANCES AND DISEASE REGISTRY. Toxicological profile for mercury. Atlanta, 1999.}

Detailed data table for the 2015 Priority List of Hazardous Substances. [Atlanta], $2015 . \quad$ Disponível em: <http://www.atsdr.cdc.gov/spl/resources/in dex.html>. Acesso em: 13 mar. 2016, 11:36:00.

Support document to the 2015 Priority List of Hazardous Substances. Atlanta, 2015. Disponível em: <http://www.atsdr.cdc.gov/spl/resources/in dex.html>. Acesso em: 13mar. 2016, 11:38:00.

\section{ASSOCIAÇÃO BRASILEIRA DE NORMAS TÉCNICAS.NBR 12235:armazenamento de resíduos sólidos perigosos. Rio de Janeiro, 1992.}

NBR 10004: resíduos sólidos classificação. 2. ed.Rio de Janeiro, 2004.

AZEVEDO, F. A. et al. Mercúrio. In: AZEVEDO, F. A.; CHASIN, A. A. M.Metais: gerenciamento da toxidade. São Paulo: Atheneu, 2003. cap. 11. p. 299352.

BRASIL. Congresso. Lei n. ${ }^{\circ} 12.305$, de 02 de agosto de 2010. Política Nacional de Resíduos Sólidos. Brasília, 2010.

Ministério do Meio Ambiente.Brasil controlará uso de mercúrio no País. Brasília, 2015. Assessoria de Comunicação. Disponível em: <http://www.mma.gov.br/index.php/comu nicacao/agenciainformma? view $=$ blog $\&$ id $=$ 1031>. Acesso em: 13 mar. 2016, 13:15:00.

Instituto Brasileiro Do Meio Ambiente e Dos Recursos Naturais Renováveis. Instrução Normativa n. ${ }^{\circ} 1$, de 25 de janeiro de 2013.Cadastro Nacional de Operadores de Resíduos Perigosos. Brasília, 2013.

GOEKING, W. Lâmpadas e leds. Revista O Setor Elétrico, São Paulo, ed. 49, nov. 2009.Disponível em: <http://www.osetoreletrico.com.br/web/ind ex.php>. Acesso em: 13 mar. 2016, 16:02:00.

GREENBERG, A.Uma breve história da química: da alquimia às ciências moleculares modernas. São Paulo: Blucher, 2009.

NASCIMENTO, E. S.; CHASIN, A. A. M.Ecotoxicologia do mercúrio e seus compostos. Salvador: CRA, 2001. Cadernos de referência ambiental, v. 1.

SILVA, C. G. M. Diagnóstico sobre a utilização das lâmpadas fluorescentes compactas (LFC) como promotoras de eficiência energética nos sistemas de 
iluminação no Brasil. São Paulo, 2008. Originalmente apresentada como dissertação de mestrado, Universidade de São Paulo, 2008.

UNITED NATIONS ENVIRONMENT PROGRAMME. [Lista de signatários e ratificações da Convenção de Minamata]. [S.1.], 2016. Disponível em: $<$ http://www.mercuryconvention.org/Coun tries/tabid/3428/Default.aspxl>. Acesso em: 13 mar. 2016, 12:50:00.

Minamata convention on mercury. Kumamoto, 2013. The Booklet of the
Convention in English (Text and Annexes).

Toolkit for identification and quantification of mercury releases: guideline for inventory level 1. Geneva, 2015. Version 1.3.

Toolkit for identification and quantification of mercury releases: reference report and guideline for inventory level 2. Geneva, 2015. Version 1.3. 